\title{
Socio-economic inequalities in physical activity practice among Italian children and adolescents: a cross-sectional study
}

\author{
Bruno Federico $\cdot$ Lavinia Falese $\cdot$ Giovanni Capelli
}

Received: 9 September 2008 / Accepted: 26 February 2009/Published online: 9 April 2009

(C) The Author(s) 2009. This article is published with open access at Springerlink.com

\begin{abstract}
Aim The aim of the study was to evaluate whether socioeconomic inequalities in the practice of physical activity existed among children and adolescents, using different indicators of socio-economic status (SES).

Subjects and methods Data were derived from the Italian National Health Interview Survey carried out in 20042005, which examined a large random sample of the Italian population using both an interviewer-administered and a self-compiled questionnaire. This study was based on a sample of 15,216 individuals aged 6-17 years. The practice of physical activity was measured on the basis of questions regarding frequency and intensity of activity during leisure time over the past 12 months. Parents' educational and occupational level, as well as family's availability of material resource, were used as indicators of SES. Multivariable logistic regression analyses were performed to estimate the contribution of each SES indicator to the practice of physical activity, adjusting for potential confounding factors. The results of the regression models are expressed as odds ratio (OR) with $95 \%$ confidence intervals ( $95 \% \mathrm{CI})$.

Results About $64 \%$ of children and adolescents in the sample declared that they participated in moderate or vigorous physical activity at least once a week. After adjustment for gender, age, parental attitudes towards physical activity and geographical area, the practice of physical activity increased with higher parental educational and occupational level and greater availability of material
\end{abstract}

B. Federico $(\bowtie) \cdot$ L. Falese $\cdot$ G. Capelli

Chair of Hygiene, Department of Health and Sport Sciences,

University of Cassino,

viale Bonomi,

03043 Cassino, FR, Italy

e-mail: b.federico@unicas.it resources. Children and adolescents whose parents held a middle or high educational title were $80 \%$ more likely to practice moderate or vigorous physical activity than subjects whose parents had a lower level of education $(\mathrm{OR}=1.80,95 \%$ CI: 1.40-2.33), while subjects with unemployed parents had an odds of practicing moderate or vigorous physical activity 0.43 times that of those children whose parents belonged to the top job occupation category (administrative/professionals). Socio-economic differences were about the same when the practice of vigorous physical activity only was considered instead of that of moderate or vigorous physical activity.

Conclusion Interventions that promote the practice of physical activity, and especially those aimed at the wider physical and social environment, are strongly needed to contrast socio-economic differences in physical activity among children and adolescents.

Keywords Children and adolescents · Physical activity Socio-economic factors

\section{Introduction}

Physical activity is a positive determinant of health and predictor of short- and long-term individual health status. Regular practice of physical activity may contribute to the prevention of the main chronic degenerative diseases (diabetes, overweight, obesity, hypertension, osteoporosis) as well as favour psychological balance, development and the improvement of social skills among children and adolescents (Hardman and Stensel 2003; Warburton et al. 2006; Washington et al. 2001). Although the positive effects on health of physical activity have largely been demonstrated, the regular practice of physical activity is 
less and less frequent in developed countries. Indeed, inactivity is one of the main causes of the current epidemics of childhood obesity (World Health Organization 2004). In children and adolescents, participation in physical activity and sports is particularly important because it is associated with lower levels of antisocial behaviour (Harrison and Narayan 2003), higher levels of positive emotional wellbeing (Steptoe et al. 1997) and greater participation in sports in adulthood (Tammelin et al. 2003).

Levels of physical activity among children and adolescents are highly variable, and few consistent correlates have been identified (Lindquist et al. 1999). These include individual, parental and environmental influences. Boys are generally more active than girls, and children are more active than adolescents (Kohl and Hobbs 1998; Seabra et al. 2007), although the latter finding was not confirmed in another study (Brodersen et al. 2007). Economic resources and familial set-up exert decisive influences on children's and adolescents' physical activity practice, with those from more advantaged familial background often having higher levels of physical activity than those in poorer families (Gordon-Larsen et al. 2000; Van der Horst et al. 2007). Both cultural and material familial resources are important predictors of physical activity: when parents provide support, their offspring are more likely to engage in physical activity (Sallis et al. 2000; Hoefer et al. 2001). However, some authors reported that once parental attitudes are taken into account, familial resources do not influence children's physical activity any longer (Kirk et al. 1997). It is therefore unclear whether the association of socioeconomic status (SES) with children's and adolescents practice of physical activity persists, when other factors, including parents' physical activity practice, are taken into account. In addition, previous studies took into account only few dimensions of SES, mainly focusing on either parental occupation or parental educational level. We therefore aimed to evaluate whether socio-economic inequalities in the practice of physical activity existed among children and adolescents, using different indicators of SES (parental education and occupation level, and family's available material resources).

\section{Methods}

We used data collected in the most recent Italian Health Interview Survey, which was performed by the Italian National Statistical Institute (Istat) in 2004-2005. This survey examined a random sample, representative of the Italian resident population, of 128,040 non-institutionalized individuals within strata of geographical area, municipality and household size (Istat-Istituto Nazionale di Statistica 2006). The non-response rate of the survey was $14.3 \%$. Our study included all subjects aged 6-17 years $(n=15,216)$ examined in the survey. From the interviewer-administered and the self-compiled questionnaire, we abstracted data on gender, age, geographical area, physical activity practice, parents' educational and occupational level, availability of material resources, perceived health status and parents' physical activity practice.

We used three different indicators of SES: parental educational level, parental occupational level and family's availability of material resources. Parental educational level was grouped into three categories according to the highest level successfully completed by one of the parents: low (primary school), middle (secondary school) and high education (university degree). Parental occupational level was grouped into five categories: administrative/professionals, self-employed, manual workers, unemployed and housewives, and those who had retired from work. Familial material resources were categorized into three classes on the basis of information about house type (country house/ cottage, apartment, council house) and the availability of the following two utilities: heating and drinkable water. Material resources were classified as less than good if at least one utility was not available or the house was poorly maintained. They were classified as good if both utilities were present and the subject lived in a properly maintained apartment, and as very good if both utilities were present and subjects lived in a properly maintained country house/ cottage.

The practice of physical activity was measured on the basis of questions regarding frequency and intensity of activity during leisure time over the past 12 months. Each subject was asked whether he/she was engaged in moderate or vigorous physical activity at least once a week. The practice of moderate physical activity was defined as the practice at least once a week of activities such as walking, doing gymnastics or cycling at moderate speed. The practice of vigorous physical activity was defined as the practice at least once a week of intense physical activity such as running, cycling or other sweat-producing activities.

Bivariate analyses were carried out using the chi-square test. Multivariable logistic regression models were used to examine the contribution of the three socio-economic indicators to children's and adolescents' participation in physical activity adjusting for potential confounding factors. Two separate logistic regression models were performed using as outcome variables the practice of moderate/vigorous activity and that of vigorous activity only. In order to increase the power of the analyses, the upper two categories of educational level (middle and high education) were collapsed into one. A further grouping was performed for geographical area (northern/central regions vs southern/insular regions). The results of the regression models are expressed as odds ratio (OR) with 95\% 
confidence intervals $(95 \% \mathrm{CI})$. The overall likelihood ratio test was used to evaluate the significance of the model, while the partial likelihood ratio test was used to determine whether adding a covariate significantly improved the model. Interaction terms were added to the model and retained if the corresponding $p$ value was lower than 0.05 . All statistical analyses were carried out using the software package Stata 10.1.

\section{Results}

Table 1 shows the characteristics of the study sample, which included 15,216 subjects aged 6-17 years, as well as their parents' characteristics. About $64 \%$ of children and adolescents in the sample reported that they participated in moderate or vigorous physical activity at least once a week. Among these, about half practised vigorous physical activity at least once a week. The percentage practising moderate or vigorous physical activity was $27.8 \%$ among children's and adolescents' fathers and $19.0 \%$ among subjects' mothers.

The practice of moderate or vigorous physical activity varied according to individual, parental and environmental characteristics: it was higher in boys (69.7\%) than in girls (58.1\%) and in subjects aged 12-14 years compared to both younger and older subjects (Table 2). Statistically significant differences emerged for all of the three indicators of SES considered: most striking were differences according to family's material resources and parental employment.

Table 3 shows the results of the regression analyses: crude and adjusted ORs of the practice of moderate or vigorous physical activity, and those of vigorous activity only, along with 95\% CI are reported. Socio-economic differences in the practice of physical activity were found at both the univariate and the multivariable analysis, although differences were somewhat attenuated in the latter. Both multivariable models were highly statistically significant, with $p$ values lower than 0.001 at the overall likelihood ratio test. The degrees of freedom were 15 for the former model (moderate or vigorous physical activity) and 14 for the latter (vigorous physical activity), the only difference between the two models being the interaction term which was not significant in the latter model.

Adjusting for all of the variables reported in the table, children and adolescents with unemployed parents had an odds of practicing moderate or vigorous physical activity 0.43 times that of those children whose parents belonged to the top job occupation category (administrative/professionals). On the other hand, subjects whose parents held a middle or high educational title were $80 \%$ more likely to practice moderate or vigorous physical activity than subjects whose parents had a lower level of education, with adjusted $\mathrm{OR}=1.80$ (95\% CI: 1.40-2.33). The
Table 1 Characteristics of the sample $(n=15,216)$

\begin{tabular}{lll}
\hline & $n$ & $\%$ \\
\hline Gender & & \\
Boys & 7,822 & 51.4 \\
Girls & 7,394 & 48.6 \\
& & \\
Age & & \\
$6-8$ & 3,612 & 23.7 \\
$9-11$ & 3,683 & 24.2 \\
$12-14$ & 3,970 & 26.1 \\
$15-17$ & 3,951 & 26.0
\end{tabular}

$\begin{array}{lll}\text { Geographical area } & & \\ \text { North-western regions } & 2,788 & 18.3 \\ \text { North-eastern regions } & 2,781 & 18.3 \\ \text { Central regions } & 2,366 & 15.6 \\ \text { Southern regions } & 5,328 & 35.0 \\ \text { Insular regions } & 1,953 & 12.8\end{array}$

Perceived health status

$$
\text { Less than good }
$$

Good or very good

14,449

Parental educational level ${ }^{\mathrm{a}}$

$\begin{array}{lll}\text { Low } & 5,396 & 35.5 \\ \text { Middle } & 7,339 & 48.2 \\ \text { High } & 2,481 & 16.3\end{array}$

Parental employment $\mathrm{t}^{\mathrm{a}}$

Administrative/professional $\quad 6,599 \quad 44.3$

Self-employed $\quad 3,511 \quad 23.6$

Manual $\quad 4,186 \quad 28.1$

Unemployed/housewife $\quad 480 \quad 3.2$

$\begin{array}{lll}\text { Retired } & 110 & 0.7\end{array}$

Material resources

$\begin{array}{lll}\text { Less than good } & 2,938 & 19.7\end{array}$

$\begin{array}{lll}\text { Good } & 10,699 & 71.8\end{array}$

$\begin{array}{lll}\text { Very good } & 1,271 & 8.5\end{array}$

Practice of moderate or vigorous physical activity

$\begin{array}{lll}\text { No } & 9,748 & 35.9\end{array}$

$\begin{array}{lll}\text { Yes } & 5,468 & 64.1\end{array}$

Father's practice of moderate physical activity

$\begin{array}{lll}\text { No } & 9,911 & 72.2\end{array}$

$\begin{array}{lll}\text { Yes } & 3,815 & 27.8\end{array}$

Mother's practice of moderate physical activity

\begin{tabular}{lll} 
No & 11,964 & 81.0 \\
Yes & 2,811 & 19.0 \\
\hline
\end{tabular}

${ }^{\mathrm{a}}$ The highest level in one of the parents 
Table 2 Percentage of subjects practising moderate or vigorous physical activity according to individual, parental and environmental characteristics

$\%$ practising moderate or vigorous physical activity

$p$ value

$\begin{array}{ll}\begin{array}{l}\text { Gender } \\ \text { Boys }\end{array} & 69.7 \\ \text { Girls } & 58.1 \\ & \\ \text { Age } & \\ 6-8 & 55.9 \\ 9-11 & 67.6 \\ 12-14 & 69.4 \\ 15-17 & 62.8\end{array}$

$<0.001$

Geographical area

North-western regions $\quad 74.6$

North-eastern regions $\quad 74.7$

Central regions $\quad 72.4$

Southern regions $\quad 52.4$

Insular regions $\quad 55.7$

Perceived health status

Less than good $\quad 57.8$

Good or very good $\quad 64.4$

$<0.001$

Parental educational level ${ }^{\mathrm{a}}$

Low

53.6

Middle

68.2

High

74.6

$<0.001$

Parental employment $\mathrm{t}^{\mathrm{a}}$

Administrative/professional $\quad 72.5$

Self-employed $\quad 63.3$

Manual 55.4

Unemployed/housewife $\quad 40.2$

Retired 63.6

$<0.001$

Material resources

Less than good $\quad 52.3$

Good 66.3

Very good $\quad 74.4$

$<0.001$

Father's practice of moderate physical activity

No $\quad 77.6$

Yes $\quad 58.8$

$<0.001$

Mother's practice of moderate physical activity

No

82.5

Yes

59.8

$<0.001$

${ }^{a}$ The highest level in one of the parents

adjusted OR of practising moderate or vigorous physical activity was 1.47 (95\% CI: 1.33-1.62) for children and adolescents with "good or very good" material resources compared to those with "less than good" ones. When parents practiced physical activity, their offspring were more likely to participate in moderate or vigorous physical activity. Living in southern Italy or in insular regions was associated with a lower participation com- 
Table 3 Crude and adjusted odds ratios $(95 \% \mathrm{CI})$ of practising moderate or vigorous physical activity and vigorous physical activity only

\begin{tabular}{|c|c|c|c|c|c|c|c|c|}
\hline & \multicolumn{4}{|c|}{ Moderate or vigorous physical activity } & \multicolumn{4}{|c|}{ Vigorous physical activity only } \\
\hline & $\mathrm{OR}^{\mathrm{a}}$ & $95 \% \mathrm{CI}$ & ORadj $^{\mathrm{b}}$ & $95 \% \mathrm{CI}$ & $\mathrm{OR}^{\mathrm{a}}$ & $95 \% \mathrm{CI}$ & ORadj $^{\mathrm{b}}$ & $95 \% \mathrm{CI}$ \\
\hline \multicolumn{9}{|l|}{ Gender } \\
\hline Boys & 1 & & 1 & & 1 & & 1 & \\
\hline Girls & 0.60 & $0.57-0.65$ & 0.63 & $0.56-0.71$ & 0.44 & $0.42-0.48$ & 0.41 & $0.37-0.44$ \\
\hline \multicolumn{9}{|l|}{ Age } \\
\hline $6-8$ & 1 & & 1 & & 1 & & 1 & \\
\hline $9-11$ & 1.64 & $1.50-1.81$ & 1.85 & $1.66-2.07$ & 1.87 & $1.68-2.09$ & 2.06 & $1.82-2.33$ \\
\hline $12-14$ & 1.79 & $1.62-1.97$ & 2.04 & $1.83-2.28$ & 2.29 & $2.07-2.55$ & 2.67 & $2.37-3.01$ \\
\hline $15-17$ & 1.33 & $1.21-1.46$ & 1.52 & $1.36-1.69$ & 2.02 & $1.82-2.25$ & 2.41 & $2.14-2.72$ \\
\hline \multicolumn{9}{|l|}{ Geographical area } \\
\hline Northern and central regions & 1 & & 1 & & 1 & & 1 & \\
\hline Southern and insular regions & 0.40 & $0.37-0.43$ & 0.48 & $0.45-0.52$ & 0.42 & $0.39-0.45$ & 0.46 & $0.42-0.50$ \\
\hline \multicolumn{9}{|l|}{ Perceived health status } \\
\hline Less than good & 1 & & 1 & & 1 & & 1 & \\
\hline Good or very good & 1.32 & $1.14-1.53$ & 1.39 & $1.17-1.66$ & 1.27 & $1.07-1.50$ & 1.45 & $1.19-1.77$ \\
\hline \multicolumn{9}{|l|}{ Parental educational level ${ }^{\mathrm{c}}$} \\
\hline Low & 1 & & 1 & & 1 & & 1 & \\
\hline Middle and high & 2.00 & $1.87-2.15$ & 1.80 & $1.40-2.33$ & 1.79 & $1.66-1.93$ & 1.37 & $1.24-1.52$ \\
\hline \multicolumn{9}{|l|}{ Parental employment ${ }^{\mathrm{c}}$} \\
\hline Administrative/professional & 1 & & 1 & & 1 & & 1 & \\
\hline Self-employed & 0.66 & $0.60-0.72$ & 0.84 & $0.76-0.93$ & 0.77 & $0.70-0.84$ & 0.91 & $0.82-1.01$ \\
\hline Manual & 0.47 & $0.43-0.51$ & 0.71 & $0.64-0.78$ & 0.57 & $0.53-0.63$ & 0.77 & $0.70-0.87$ \\
\hline Unemployed/housewife & 0.26 & $0.21-0.31$ & 0.43 & $0.34-0.56$ & 0.30 & $0.23-0.40$ & 0.46 & $0.32-0.66$ \\
\hline Retired & 0.66 & $0.45-0.98$ & 0.80 & $0.49-1.29$ & 0.66 & $0.43-1.01$ & 0.94 & $0.56-1.56$ \\
\hline \multicolumn{9}{|l|}{ Material resources } \\
\hline Less than good & 1 & & 1 & & 1 & & 1 & \\
\hline Good or very good & 1.87 & $1.72-2.03$ & 1.47 & $1.33-1.62$ & 1.77 & $1.61-1.95$ & 1.44 & $1.28-1.61$ \\
\hline \multicolumn{9}{|c|}{ Father's practice of physical activity } \\
\hline No & 1 & & 1 & & 1 & & 1 & \\
\hline Yes & 2.43 & $2.23-2.64$ & 1.63 & $1.48-1.79$ & 1.77 & $1.61-1.95$ & 1.44 & $1.28-1.61$ \\
\hline \multicolumn{9}{|c|}{ Mother's practice of physical activity } \\
\hline No & 1 & & 1 & & 1 & & 1 & \\
\hline Yes & 3.17 & $2.86-3.51$ & 2.15 & $1.91-2.43$ & 2.07 & $1.90-2.26$ & 1.56 & $1.41-1.72$ \\
\hline Girl*middle/high education & & & 0.83 & $0.71-0.97$ & & & & \\
\hline
\end{tabular}

${ }^{\mathrm{a}}$ Crude odds ratio

${ }^{\mathrm{b}}$ Adjusted odds ratio: the model includes all variables reported in the table

${ }^{\mathrm{c}}$ The highest level in one of the parents 
pared to other regions, with adjusted $\mathrm{OR}=0.48(95 \%$ CI: $0.45-0.52$ ).

When the practice of vigorous physical activity was considered instead of that of moderate or vigorous physical activity, results of the logistic regression analysis were largely overlapping. All three socio-economic indicators considered were significantly associated with the practice of vigorous physical activity: the higher the status, the more frequent the practice of vigorous physical activity, although inequalities were generally smaller compared to the model with moderate or vigorous physical activity as the outcome variable.

Since we hypothesized that parental characteristics could have a different effect depending on their offspring age and gender, we tested for interaction between parent's education and occupation and their offspring demographics. In the multivariable model with moderate or vigorous physical activity as the outcome variable, the only significant interaction was found between parental education and gender, showing the different influence parent's educational level has on their daughters and sons. No significant interaction was found for the model with vigorous physical activity as the outcome variable.

\section{Discussion}

\section{Summary of the main findings}

In our study, adjusting for individual and area-level variables, all three indicators of SES (parental education and occupational level, and availability of material resources) were significantly associated with children's and adolescents' physical activity practice. The practice of physical activity increased with higher parental educational and occupational level and greater availability of material resources.

\section{Limitations of the study}

Firstly, physical activity measurement relied on selfreported data. Physical activity has traditionally been measured with surveys and recall instruments, which are often preferred to objectively measured physical activity because of greater convenience (Heitzler et al. 2006; Scully et al. 2007). A widely used tool is the International Physical Activity Questionnaire, which is usually applied for monitoring population levels of physical activity among adults (Craig et al. 2003). Among children, the validity of similar questionnaires is limited (Lachat et al. 2008). Some studies reported a moderate to good agreement between self-reported and objectively measured physical activity (Epstein et al. 1996; Sallis et al. 1996). Our measurement of physical activity may have suffered from some misclassi- fication. However, if the misclassification was not differential, that is, the misclassification did not significantly vary by socio-economic indicator, the result would be a dilution of the effect. In other words, the socio-economic differences in physical activity practice found in this study are probably smaller than they actually are.

A second limitation of the study is the cross-sectional design, which is of limited value in the search for causal explanation because exposure and outcome are measured at the same time. However, it is likely that all three socioeconomic determinants under investigation preceded in time, and were not followed by, children's and adolescents' practice of physical activity. A third limitation is the lack of information in the available data set on those psychological factors which may influence the participation in physical activity, such as anxiety and self-esteem. Accounting for these factors would probably have attenuated the effect of parental socio-economic characteristics and attitudes towards physical activity, but it is unlikely that the effect of all three measures of SES would have been cancelled out.

\section{Comparison with other studies}

Several studies found a positive association between SES and children and adolescents' physical activity practice. According to a recent review, mother's educational level and family income were consistently associated with physical activity practice among adolescents (Ferreira et al. 2007). In Finland, parental income and education were directly related to adolescents' physical activity or engagement in sport activities (Kantomaa et al. 2007). Among adolescents of central and southern Italy, a positive association between extracurricular physical activity and parental SES was found (La Torre et al. 2006). Contrary to the finding of Wagner et al. (2004), our results indicate an effect of familial available material resources on offspring physical activity also after controlling for parental sport habits. Our finding that available material resources limit the possibility to practice physical activity is justified, among others, by the study performed by Kirk et al. on 220 families in the Queensland and Victoria areas in Australia (Kirk et al. 1997). In this study, parents made a substantial contribution in terms of financial support to their children's participation in junior sport activities, given the yearly cycle of training and competition, distance from facilities and coaching, and costs associated with coaching, equipment and uniforms.

A more difficult access to sport facilities may probably explain the large heterogeneity in physical activity practice we found within the same country, namely the existence of a north-south gradient in physical activity practice. A study conducted by the Italian National Olympic Committee (CONI) found a huge gradient in the number of infra- 
structures within Italy, with more structures being present in northern regions (CONI 2004). Focus group discussions revealed that safe, convenient, inexpensive facilities were considered essential for participation in physical activity especially by adolescents of lower SES, while different factors, such as fun, perceived competence and friends' support, were more relevant among youth of higher SES (Humbert et al. 2006). Other possible explanations of the north-south gradient are the higher level of social deprivation in southern regions and cultural factors that value physical activity differently.

Implications for policy

Since children and adolescents spend a large part of their time at school, school environment may strongly influence their engagement in physical activity. The implementation of school policies related to physical activity, like physical education classes, leisure time free use of playing fields, size and state of conservation of school facilities, and existence of parental supervision or organized activities, was associated with higher levels of children's and adolescents' physical activity (Ferreira et al. 2007), although there is considerable debate on the effect of compulsory school physical activity (Seabra et al. 2007; Cleland et al. 2008). A recent study from the Netherlands emphasizes the contribution of physical environment features, such as housing type, green spaces and traffic levels (de Vries et al. 2007). Since it is increasingly recognized that the wider physical and social environment is an important determinant of health and health behaviour, the availability of material infrastructure, such as children's playgrounds and sport facilities that are easily accessible as well as the social context of the community in which children and adolescents live, may increase their participation in physical activity (McKay et al. 2007).

\section{Conclusions}

Socio-economic differences in the practice of physical activity are present during childhood and adolescence and are of considerable extent. Interventions that promote the practice of physical activity, and especially those aimed at creating supportive neighborhood environments in more disadvantaged areas as well as at increasing accessibility to playgrounds and sport facilities, are strongly needed in order to contrast socio-economic differences in physical activity among children and adolescents.

Acknowledgements We wish to thank Dr. Saverio Tomaiuolo, Lecturer in English Literature, Language and Translation, Department of Health and Sport Sciences, University of Cassino, for his revision of the manuscript.
Conflict of interest The authors confirm that there are no relevant associations that might pose a conflict of interest.

Funding This study was partially funded by the Department of Health and Sport Sciences, University of Cassino.

Open Access This article is distributed under the terms of the Creative Commons Attribution Noncommercial License which permits any noncommercial use, distribution, and reproduction in any medium, provided the original author(s) and source are credited.

\section{References}

Brodersen NH, Steptoe A, Boniface DR, Wardle J (2007) Trends in physical activity and sedentary behaviour in adolescence: ethnic and socioeconomic differences. Br J Sports Med 41(3):140-144. doi:10.1136/bjsm.2006.031138

Cleland V, Dwyer T, Blizzard L, Venn A (2008) The provision of compulsory school physical activity: associations with physical activity, fitness and overweight in childhood and twenty years later. Int J Behav Nutr Phys Act 5:14. doi:10.1186/1479-5868-5-14

CONI (2004) La situazione degli impianti sportivi in Italia al 2003. Ministero per i Beni e le Attività Culturali, Consiglio Nazionale dell'Economia e del Lavoro, Rome

Craig CL, Marshall AL, Sjöström M, Bauman AE, Booth ML, Ainsworth BE, Pratt M, Ekelund U, Yngve A, Sallis JF, Oja P (2003) International physical activity questionnaire: 12-country reliability and validity. Med Sci Sports Exerc 35(8):13811395

de Vries SI, Bakker I, van Mechelen W, Hopman-Rock M (2007) Determinants of activity-friendly neighborhoods for children: results from the SPACE study. Am J Health Promot 21(4 Suppl): 312-316

Epstein LH, Paluch RA, Coleman KJ, Vito D, Anderson K (1996) Determinants of physical activity in obese children assessed by accelerometer and self-report. Med Sci Sports Exerc 28(9):11571164

Ferreira I, van der Horst K, Wendel-Vos W, Kremers S, van Lenthe FJ, Brug J (2007) Environmental correlates of physical activity in youth-a review and update. Obes Rev 8(2):129-154. doi:10.1111/j.1467-789X.2006.00264.x Review

Gordon-Larsen P, McMurray RG, Popkin BM (2000) Determinants of adolescent physical activity and inactivity patterns. Pediatrics 105(6):E83. doi:10.1542/peds.105.6.e83

Hardman AE, Stensel DJ (2003) Physical activity and health: the evidence explained. Routledge, London

Harrison PA, Narayan G (2003) Differences in behavior, psychological factors, and environmental factors associated with participation in school sports and other activities in adolescence. J Sch Health 73(3):113-120

Heitzler CD, Martin SL, Duke J, Huhman M (2006) Correlates of physical activity in a national sample of children aged 9-13 years. Prev Med 42(4):254-260

Hoefer WR, McKenzie TL, Sallis JF, Marshall SJ, Conway TL (2001) Parental provision of transportation for adolescent physical activity. Am J Prev Med 21(1):48-51. doi:10.1016/S0749-3797(01)00314-2

Humbert ML, Chad KE, Spink KS, Muhajarine N, Anderson KD, Bruner MW, Girolami TM, Odnokon P, Gryba CR (2006) Factors that influence physical activity participation among high- and low-SES youth. Qual Health Res 16(4):467-483. doi:10.1177/ 1049732305286051 
Istat-Istituto Nazionale di Statistica (2006) Il sistema di indagini sociali multiscopo. Istat, Rome. Available at http://www.istat.it/dati/ catalogo/20060615_00/met_\%20norme_06_31_il_sistema_di_ indagini_multiscopo.pdf

Kantomaa MT, Tammelin TH, Näyhä S, Taanila AM (2007) Adolescents' physical activity in relation to family income and parents' education. Prev Med 44(5):410-415. doi:10.1016/j. ypmed.2007.01.008

Kirk D, Carlson T, O'Connor A, Burke P, Davis K, Glover S (1997) The economic impact on families of children's participation in junior sport. Aust J Sci Med Sport 29(2):27-33

Kohl HW 3rd, Hobbs KE (1998) Development of physical activity behaviors among children and adolescents. Pediatrics 101(3 Pt 2):549-554. doi:10.1542/peds.101.3.S1.549 Review

Lachat CK, Verstraeten R, le Khanh NB, Hagströmer M, Khan NC, Van Ndo A, Dung NQ, Kolsteren PW (2008) Validity of two physical activity questionnaires (IPAQ and PAQA) for Vietnamese adolescents in rural and urban areas. Int J Behav Nutr Phys Act 5:37

La Torre G, Masala D, De Vito E, Langiano E, Capelli G, Ricciardi W, Physical Activity and Socio-Economic Status collaborative group (2006) Extra-curricular physical activity and socioeconomic status in Italian adolescents. BMC Public Health 6:22. doi:10.1186/1471-2458-6-22

Lindquist CH, Reynolds KD, Goran MI (1999) Sociocultural determinants of physical activity among children. Prev Med 29 (4):305-312. doi:10.1006/pmed.1999.0546

McKay CM, Bell-Ellison BA, Wallace K, Ferron JM (2007) A multilevel study of the associations between economic and social context, stage of adolescence, and physical activity and body mass index. Pediatrics 119(Suppl 1):S84-S91. doi:10.1542/peds.2006-2089M

Sallis JF, Strikmiller PK, Harsha DW, Feldman HA, Ehlinger S, Stone EJ, Williston J, Woods S (1996) Validation of interviewer- and self-administered physical activity checklists for fifth grade students. Med Sci Sports Exerc 28(7):840-851

Sallis JF, Prochaska JJ, Taylor WC (2000) A review of correlates of physical activity of children and adolescents. Med Sci Sports Exerc 32(5):963-975
Scully M, Dixon H, White V, Beckmann K (2007) Dietary, physical activity and sedentary behaviour among Australian secondary students in 2005. Health Promot Int 22(3):236-245

Seabra AF, Mendonca DM, Thomis MA, Peters TJ, Maia JA (2007) Associations between sport participation, demographic and socio-cultural factors in Portuguese children and adolescents. Eur J Public Health 18:25-30

Steptoe A, Wardle J, Fuller R, Holte A, Justo J, Sanderman R, Wichstrøm L (1997) Leisure-time physical exercise: prevalence, attitudinal correlates, and behavioral correlates among young Europeans from 21 countries. Prev Med 26(6):845-854. doi:10.1006/pmed.1997.0224

Tammelin T, Näyhä S, Hills AP, Järvelin MR (2003) Adolescent participation in sports and adult physical activity. Am J Prev Med 24(1):22-28. doi:10.1016/S0749-3797(02)00575-5

Van der Horst K, Paw MJ, Twisk JW, Van Mechelen W (2007) A brief review on correlates of physical activity and sedentariness in youth. Med Sci Sports Exerc 39(8):1241-1250. doi:10.1249/ mss.0b013e318059bf35

Wagner A, Klein-Platat C, Arveiler D, Haan MC, Schlienger JL, Simon C (2004) Parent-child physical activity relationships in 12-year old French students do not depend on family socioeconomic status. Diabetes Metab 30(4):359-366. doi:DM-04-200430-4-1262-3636-101019-ART9

Warburton DE, Nicol CW, Bredin SS (2006) Health benefits of physical activity: the evidence. CMAJ 174(6):801-809

Washington RL, Bernhardt DT, Gomez J, Johnson MD, Martin TJ, Rowland TW, Small E, LeBlanc C, Krein C, Malina R, Young JC, Reed FE, Anderson S, Bolduc S, Bar-Or O, Newland H, Taras HL, Cimino DA, McGrath JW, Murray RD, Yankus WA, Young TL, Fleming M, Glendon M, Harrison-Jones L, Newberry JL, Pattishall E, Vernon M, Wolfe L, Li S, Committee on Sports Medicine and Fitness and Committee on School Health (2001) Organized sports for children and preadolescents. Pediatrics 107(6):1459-1462

World Health Organization (2004) Global strategy on diet, physical activity and health. Physical activity and young people. Available at http://www.who.int/dietphysicalactivity/factsheet_young_people/ en/index.html. Accessed 7 Jul 2008 